\title{
КЛИНИКО-ЭЛЕКТРОМИОГРАФИЧЕСКАЯ ХАРАКТЕРИСТИКА ВИТАМИН В12 ДЕФИЦИТНЫХ ПОЛИНЕЙРОПАТИЙ
}

\author{
Оржешковский В.В.* \\ Национальная медиџинская академия последипломного образования имени П.Л.Шупика, кафедра \\ неврологии - 2, Киев, Украина
}

В статье дана клиническая и электромиографическая характеристика 27 пациентов с полинейропатией, обуслов-

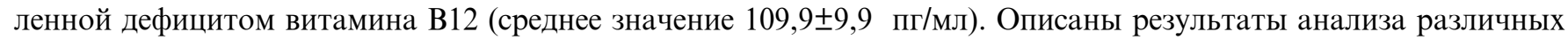
вариантов течения заболевания и проведенного корреляционного анализа клинических, лабораторных и нейрофизиологических показателей. Поражение периферической нервной системе сочеталось с гематологическими проявлениями дефицита витамина В12 лишь у 5 пациентов (18,5\%), преобладающей формой полинейропатии была с преимущественным поражением сенсорных волокон (15; 55,6\%), однако в 44,4\% (12) случаев наряду с сенсорными, поражались и моторные волокна с соответствующей клиникой. Нейропатический болевой синдром был не характерным. Сывороточный уровень витамина В12 имел обратную корреляционную связь с возрастом. Помимо этого показаны корреляционные соотношения клинических и нейрофизиологических показателей, характеризующие особенности течения заболевания.

Ключевые слова: Витамин В12 дефицитное состояние, дистальная симметричная полинейропатия, стимуляционная электромиография.

Витамин В12 дефицитное состояние и ассоцированное с этим состоянием поражение периферической нервной системы не теряют своей актуальности и в настоящее время. Согласно проведенному в США с 1999 по 2002 г. национальному исследованию здоровья и питания распространенность дефицита (в сыворотке крови витамина В12<148 пмоль/л) варьировала в возрастной группе 20-39 лет около $3 \%, 40-59$ лет около $4 \%$ и у лиц в возрасте 70 лет и более около 6\%. Пограничный дефицит (сывороточное содержание витамина В12: 148-221 пмоль/л) встречался чаще и составил в возрасте 20-59 лет около 14-16\%, старше 60 лет $>20 \%$ [2]. Причины дефицита витамина В12 могут быть различными: низкое потребление витамина В12, нарушение всасывания (атрофический гастрит, хронический гастрит, Helicobacter Pylori ассоциированный гастрит, после резекции желудка и подвздошной кишки, бактериальный рост в тонком кишечнике, хроническая поджелудочная экзокринная недостаточность, болезнь Крона, целиакия, ахлоргидрия), беременность, прием оральных контрацептивов, метформина, ингибиторов протонного насоса и антагонистов Н2-рецепторов гистамина, аутоиммунное поражение (пернициозная анемия и синдром Шегрена), генетический дефицит транскобаламина II [3]. В12-дефицитное состояние вызывает поражение периферической нервной системы (ПНС) в подавляющем большинстве случаев по типу дистальной симметричной аксональной полинейропатии с преимущественным поражением сенсорных волокон [1,5]. Помимо поражений ПНС в большинстве случаев присутствует мегалобластная анемия, а в далеко зашедших случаях панцитопения (с присоединяющимися лейкоцитопенией и тромбоцитопенией), а также возможны синдромы поражения центральной нервной системы (ЦНС), в первую очередь и чаще демиелинизация задних канатиков и кортикоспинальных трактов спинного мозга, снижение памяти, изменения личности, деменция, депрессия [4].

Материал и методы исследования. Под нашим наблюдением находилось 27 пациентов в возрасте от 20 до 59 лет (средний возраст 45,5 $\pm 2,3$ лет) (15 мужчин и 12 женщин), В12дефицитное состояние которых было подтверждено лабораторно. Содержание В12 варьировало от 44,1 до 157,6 пг/мл (среднее

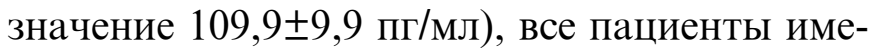
ли признаки поражения ПНС, основу которой составила дистальная симметричная полинейропатия (ДСП). Всем пациентам было проведено клинико-неврологическое исследование с определением баллов по шкале TCNSS (Toronto Clinical Neuropathy Scoring e-mail: neurology-education@ukr.net 
System), нейропатического дисфункционального счета (НДС) и по опроснику PainDetect, a также стимуляционная электромиография на аппарате "Нейрон-Спектр-4/ВПМ" (Российская Федерация) с исследованием М-ответа и скорости распространения возбуждения по моторным волокнам (СРВм) n.tibialis, n.peroneus, n.medialis, n.ulnaris, a также поздних ответов (F-волна) и скорости распространения возбуждения по сенсорным волокнам (CPBc) n.saphenus, n.suralis, n.medialis, n.ulnaris. Полученный материал был обработан методами описательной статистики, корреляционного анализа и непараметрической статистики с помощью пакета "Statistica 10".

Результаты исследования и обсуждение. В результате проведенного исследования получены следующие результаты. Средний балл составил по шкале TCNSS 9,6 0 0,4, а по шкале НДС 10,2 $\pm 0,7$, что соответствует умеренно выраженной полинейропатии, клиника которой и была представлена у большинства пациентов (24) и у 3 пациентов количество баллов соответствовало выраженной ПНП. Нейропатический болевой синдром не был характерен для нашей группы пациентов и по опроснику PainDetect ни один пациент не набрал необходимых 18 баллов, отмечались лишь незначительные локальные боли в области суставов. В группе исследованных пациентов гематологические проявления в виде мегалобластной анемии были представлены лишь у 5 пациентов, что еще раз подтверждает тот факт, что поражение нервной системы при дефиците витамина В12 может быть без гематологических проявлений, которые не являются обязательным признаком этого дефицита. А уровень витамина В12 у этих пациентов варьировал от 113 до 143 пг/мл. У 2 пациентов на фоне ДСП отмечались признаки поражения коротких ветвей правого плечевого сплетения с грубыми атрофиями мышц плечевого пояса. У 6 пациентов отмечалось вовлечение в патологический процесс задних канатиков спинного мозга и кортикоспинальных трактов и у 1 пациента признаков поражения мозжечка, которые не коррелировали ни с возрастом ни с уровнем вита- мина В12. У всех пациентов отмечалось смешанное поражение нервных волокон ПНС с преобладанием аксоно- либо миелинопатии без четкого размежевания. По пораженным типам волокон группа пациентов разделилась следующим образом - сочетанное поражение моторных и сенсорных волокон - 12 пациентов и преимущественное поражение сенсорных волокон - 15. В результате проведенного корреляционного анализа выявлена обратная корреляционная зависимость сывороточного уровня витамина В12 и возраста $(\mathrm{r}=0,54)$. Также выявлена интересная корреляционная зависимость уровня витамина В12 и наличия блоков проведения по n.tibialis $(\mathrm{r}=0,6)$ и значимого снижения амплитуды Мответа n.peroneus $(\mathrm{r}=0,69)$, что может свидетельствовать о следующей закономерности чем ниже уровень витамина В12, тем выше вероятность преобладающего аксонопатического поражения, в частности n.peroneus, и чем этот показатель выше при дефиците витамина В12, тем выше вероятность миелинопатии, в частности n.tibialis.

Также результаты по шкале TCNSS коррелировали с показателями резидуальной латентности n.tibialis $(\mathrm{r}=0,51)$, снижением амплитуды М-ответа n.peroneus $(\mathrm{r}=0,69), \mathrm{CPBc}$ n.saphenus $(\mathrm{r}=0,59)$, что возможно позволяет рассматривать данные ЭМГ показатели как нейрофизиологические эквиваленты TCNSS. Наличие снижения амплитуды М-ответа n.tibialis коррелировало с изменениями показателей F-волны $(\mathrm{r}=0,65)$ в виде снижения скорости проведения по проксимальным отделам, может служить дополнительным маркером вовлечения этих отделов в патологический процесс при данной патологии. Изменения СРВм n.tibialis коррелировало с изменениями СРВм n.peroneus $(\mathrm{r}=0,54)$, n.medialis $(\mathrm{r}=0,67)$, n.ulnaris $(\mathrm{r}=0,53)$, что объединяет эти показатели при наличии преобладающей миелинопатии. Интересной является и обратная корреляционная зависимость между показателями СРВм и СРBc: СРВм n.tibialis и CPBc n.ulnaris $(r=0,65)$ и n.suralis $(r=0,79)$; СРВм n.medialis CPBc n.ulnaris $(r=0,65)$. Также та же тенденция просматривается между 
показателями резидуальной латентности (РЛ) n.tibialis и $\mathrm{CPBc}$ n.ulnaris $(\mathrm{r}=0,56)$ и $\mathrm{CPBc}$ n.saphenus $(\mathrm{r}=0,95)$. Эта особенность может свидетельствовать о преобладающей форме ДСП у конкретных пациентов в виде преимущественно сенсорной либо моторной формы. СРСс коррелируют также и между собой: CPCc n.ulnaris и n.saphenus $(\mathrm{r}=0,7)$, СРCс n.medialis и n.suralis $(\mathrm{r}=0,67)$, что свидетельствует о диффузности и однотипности поражения периферических нервов на верхних и нижних конечностях.

В результате выше изложенного можно сделать следующие выводы.

1. Наличие гематологических проявлений не является облигатным признаком, обусловленного витамин В12 дефицитом поражения ПНС, в частности дистальной симметричной полинейропатии, что усложняет диагностику и требует учета особенностей клинической картины, неврологического статуса и нейрофизиологических показателей.

2. Несмотря на данные литературы о том, что данная группа поражений ПНС представлены в виде дистальной симметричной аксональной полинейропатии с преимущественным поражением сенсорных волокон, возможно в достаточно большом проценте случаев (в нашей группе 44,4\%) сочетанное поражение моторных и сенсорных волокон, со значимыми проявлениями в виде в некоторых

\section{ЛИТЕРАТУРА}

1. Bernhard Neundörfer, Dieter Heu?. Polyneuropathien. Georg Thieme Verlag, Stuttgart, 2007. 129s.

2. Lindsay H Allen. How common is vitamin B-12 deficiency?/ Am J Clin Nutr 2009;89(suppl):693-6

3. Michael J Shipton, Jecko Thachil. Vitamin B12 deficiency - A 21st century perspective / Clinical Medicine случаях достаточно выраженных парезов, а также возможно вовлечение в патологический процесс структур плечевого сплетения (в наших наблюдениях асимметрично справа). Нейропатический же болевой синдром в наших наблюдениях не является характерным.

3. Выявленная корреляционная зависимость сывороточного уровня витамина В12 обратная с возрастом, а также прямая с наличием блоков проведения по n.tibialis и обратная с значимым снижением амплитуды М-ответа n.peroneus, что может свидетельствовать о возможной закономерности - чем ниже уровень витамина В12, тем выше вероятность преобладающего аксонопатического поражения, в частности n.peroneus, и чем этот показатель выше при дефиците витамина В12, тем выше вероятность миелинопатии, в частности n.tibialis. Также возможно более выраженное снижение уровня витамина В12 с увеличением возраста.

4. Имеются значимые корреляционные зависимости, которые характеризуют особенности клинической картины и их связь с нейрофизиологическими показателями, а также между самими нейрофизиологическими показателями, что позволяет точнее определить преобладающий патогенетический механизм поражения (аксоно- либо миелинопатия), а также преобладающее вовлечение моторных и сенсорных волокон.

2015 Vol 15, No 2: 145-50

4. Robert C. OH, David L.Brown. Vitamin B12 Deficiency/ Am Fam Physician. 2003 Mar 1; 67(5): 979-986.

5. Textbook of Peripheral Neuropathy/ editor Peter D. Donofrio. Demos Medical Publishing, New York, 2012. $475 \mathrm{p}$.

\title{
XÜLASə
}

\section{VITAMIN B12 DEFISITLI POLINEYROPATIYYLARIN KLINIK-ELEKTROMIOQRAFIK XARAKTERISTIKASI}

\author{
Orjeşkovskiy V.V. \\ P.L.Şupik adına Diplomdan sonrakı milli tibb akademiyası, Kiyev, Ukrayna
}

Məqalədə vitamin B12 defisitli polineyropatiyalı 27 pasiyentin klinik-elektromioqrafik xarakteristikası verilmişdir (orta göstərici 109,9 $\pm 9,9$ pq/ml). Xəstəliyin gedişinin müxtəlif variantlarının və klinik, laborator, ney- 
rofizioloji göstəricilərin korrelyasion analizinin nəticələri təsvir edilmişdir. Ancaq 5 pasiyentdə (18,5\%) periferik sinir sisteminin zədələnməsi B12 vitamininin defisitinin hematoloji göstəriciləri ilə müştərək olmuşdur, polineyropatiyanın ən çox rast gəlinən forması daha çox sensor liflərin zədələnməsi ilə gedən forma (15; $55,6 \%$ ) olmuşdur, amma 44,4\% (12) hallarda kliniki mənzərəyə uyğun, sensor liflərlə birgə motor liflər də zədələnmişdir. Neyropatik ağrı sindromu xarakter deyildi. Vitamin B12-nin qanda səviyyəsi yaşla əks korrelyasion əlaqəyə malik olmuşdur. Bundan başqa xəstəliyinin gedişinin xüsusiyyətlərini xarakterizasiya edən klinik və neyrofizioloji göstəricilərin korrelyasion əlaqələri göstərilmişdir.

Açar sözlər: Vitamin B12 defisiti vəziyyəti, distal simmetrik polineyropatiya, stimulyasion elektromioqrafiya

\title{
SUMMARY
}

\section{CLINICAL AND ELECTROMYOGRAPHIC CHARACTERISTICS B12 DEFICIENT POLYNEUROPATHY}

\author{
Orzheshkovskyi V.V. \\ Shupyk National Medical Academy of Postgraduate Education, Kiev, Ukraine
}

The paper presents a clinical and electromyographic characteristics of 27 patients with polyneuropathy due to vitamin B12 deficiency (average of 109,9 $\pm 9,9 \mathrm{pg} / \mathrm{ml}$ ). The results of the analysis of the different variants of the disease and the correlation analysis conducted clinical, laboratory and neurophysiological parameters. The defeat of the peripheral nervous system, combined with hematological symptoms of vitamin B12 deficiency in only 5 patients $(18.5 \%)$ was the predominant form of polyneuropathy with a primary lesion of sensory fibers $(15 ; 55.6 \%)$, but 44.4\% (12) cases along with touch, amazed and motor fibers with appropriate clinic. Neuropathic pain was not typical. Serum levels of vitamin B12 has an inverse correlation with age. In addition, the ratio shows the correlation of clinical and neurophysiological parameters characterizing features of the disease.

Keywords: Vitamin B12 deficiency states, distal symmetric polyneuropathy, stimulating electromyography.

Redaksiyaya daxil olub: 05.10.2015

Çapa tövsiy olunub: 28.10 .2015

Rəyçi: t.ü.f.d. Oliyev R.R. 